\title{
Performance Investigation and Structure Optimization of a Flat Dual-Function Solar Collector
}

\author{
Jinwei Ma, ${ }^{1}$ Haitao Wang, ${ }^{1}$ Yanping Wang, ${ }^{1}$ Wei Sun, ${ }^{2}$ and Jie $\mathrm{Ji}^{2}$ \\ ${ }^{1}$ Anhui Advanced Technology Research Institute of Green Building, Anhui Jianzhu University, Hefei 230601, China \\ ${ }^{2}$ Department of Thermal Science and Energy Engineering, University of Science and Technology of China, Hefei 230026, China
}

Correspondence should be addressed to Jinwei Ma; majw@mail.ustc.edu.cn and Haitao Wang; htwang@163.com

Received 8 January 2015; Revised 22 May 2015; Accepted 3 June 2015

Academic Editor: Sauro Filippeschi

Copyright (C) 2015 Jinwei Ma et al. This is an open access article distributed under the Creative Commons Attribution License, which permits unrestricted use, distribution, and reproduction in any medium, provided the original work is properly cited.

The performance of a dual-function solar collector (DFSC) that can work as either water heater or air heater depending on seasonal requirement is investigated via both experimental and numerical approaches in this paper. The numerical results are well consistent with the experimental results. Daily efficiency of the thermosiphon system with DFSC is more than 55\% in water heating mode and the instantaneous air heating efficiency of the collector reaches $60 \%$. The effects of inner parameters on the thermal efficiency of the collector are analyzed by numerical simulations of the operation of DFSC in two working modes. It is found that the depths of the two air channels in DFSC have an optimal range suitable for both working modes. The thickness of back insulation should be no less than $0.06 \mathrm{~m}$ to prevent heat loss via backboard, and the diameter and number of copper tubes show notable effect on the efficiency of DFSC in water heating mode but slight effect in air heating mode.

\section{Introduction}

China is by far the largest market for solar water heaters. Due to its advantage in adapting building envelope, flat-plate solar water heater is utilized widely in southern China to make domestic hot water. Influence of building integration on the performance of different solar collectors has been widely investigated $[1,2]$. But in central and northern China, because of cold climate, antifreeze fluid has to be used as heat transfer agent to overcome water-freezing problems in flatplate water heaters [3], which however increases both the cost of product and the effort of maintenance. As, in cold days in these regions, energy consumption is prominent for space heating in buildings, an alternative solar collector named as dual-function solar collector (DFSC) has been proposed, which operates not only as air heater for space heating in cold winter but also as water heater in other warm seasons [4-6]. By the seasonal alternation between the two heating modes, the collector has no water-freezing problems and a higher annually utilization ratio.

The DFSC is modified from conventional flat-plate collector by broadening the air gap between the absorber plate and the backboard, which together with the air gap between the absorber plate and the cover glazing functions as a channel for air flow in air heating mode [7]. Effect of the structure of air channel on efficiency of solar air heaters has been intensely investigated. Different types of fins have been used to enhance the heat transfer in air channel [8-10]. Baffles have been applied to further increase the thermal efficiency of solar air heaters [11]. The depth of air channel has been found to have notable influence on performance of solar air heaters [7]. The gap between absorber plate and glazing should be of an appropriate value to curb heat losses via the top of solar water heater $[12,13]$. These structural adjustments for solar air heater and water heater, however, are different and even contradictory and hence impossible to be directly applied to DFSC. Aiming to optimize the structure parameters of DFSC, a dynamic numerical model to simulate the operation of DFSC is developed in this paper. Performance of DFSC is investigated by both experimental and numerical approaches. Compared with the experimental data, the numerical model is validated. Effect of different inner parameters on the efficiency of DFSC in two heating modes is analyzed based on numerical results. 


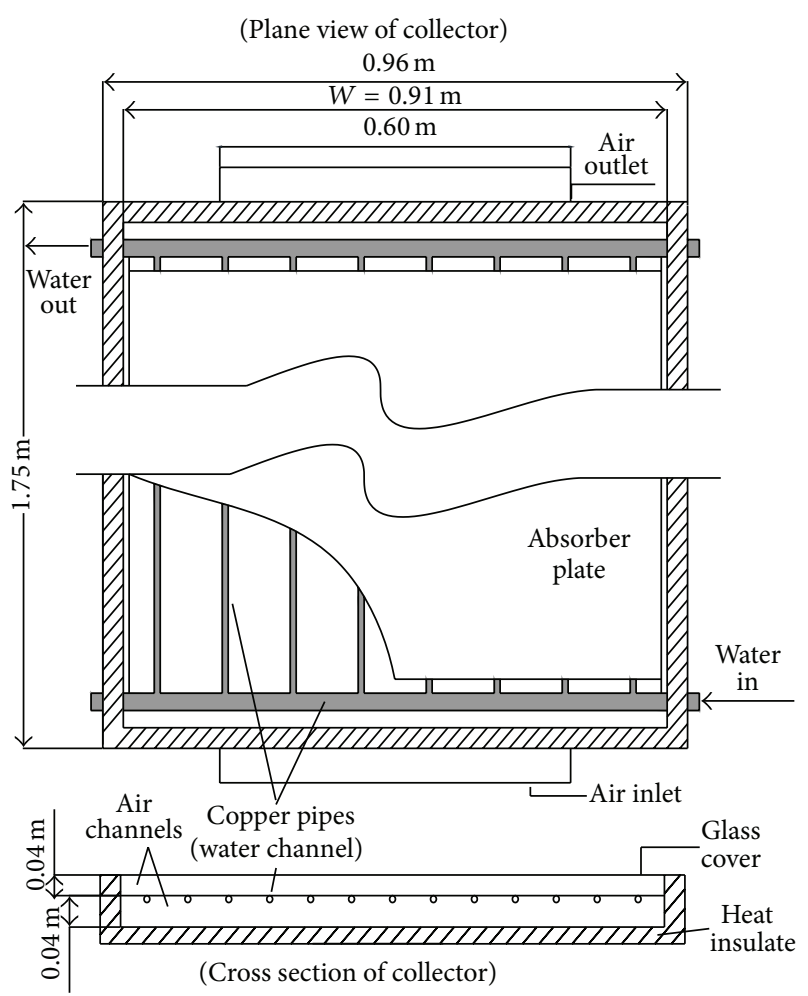

FIGURE 1: Schematic diagram of the dual-function solar collector.

\section{Experiment Setup for Testing DFSC}

2.1. Description of the DFSC. Structure of the dual-function collector is shown in Figure 1. Copper tubes are welded on the back of an aluminum plate, the front of which is coated with selective material to absorb incident solar radiation. The plate is fixed at the intermediate depth of the gap between glazing and backboard, so as to form two air channels. The absorber plate and the interior plate of backboard have the same area, and copper tubes have the same length with the absorber plate and the backboard. In water heating mode, solar energy is absorbed by the plate and transferred to the flowing water in the tubes, and air inlet and outlet are closed by filling with insulation material to prevent heat losses in water heating mode to prevent heat losses. In air heating mode, solar energy is transferred to the flowing air in the channels. The cover glass is of $0.0032 \mathrm{~m}$ thickness with the aperture of $1.65 \mathrm{~m}$ in length and $0.91 \mathrm{~m}$ in width. The depths of upper and lower air channels are both of $0.04 \mathrm{~m}$. The cross-sectional area of air inlet and outlet is $0.6 * 0.04 \mathrm{~m}^{2}$. The backboard is composed of two iron plates with the both thickness of $0.004 \mathrm{~m}$, middle layer of which is glass fiber with the thickness of $0.015 \mathrm{~m}$ for thermal insulation. Glass fiber is also mounted as thermal insulation material at the sides of the collector.

2.2. Experimental Setup. The experiments of the collector in water heating and air heating modes were set up separately as shown in Figures 2 and 3, respectively.

In water heating mode, the collector was connected to a storage water tank of $120 \mathrm{~L}$ with pipes and associated valves. In the experiment, water was filled into the system in early morning, andmeasurement lasted from morning till late afternoon. The temperatures of water at inlet and outlet, absorber plate surface, glass cover surface, air in the upper and lower channels, interior and exterior surfaces of backboard, and five equidistant points in the water tank were measured.

The experiment of collector in air heating mode was set up according to the ASHRAE standard [14]. Open-loop testing method was adopted. A vortex type air pump was used to drive airflow and a valve was used to control flow rate. The air flow rate was measured by a gas mass flow meter. Temperatures of air at both inlet and outlet of the collector were measured.

The experiments were carried out in good weather conditions in Hefei from March to June. Temperatures of the DFSC test system and the ambient air were measured by copper-constantan thermocouples with the accuracy of $\pm 0.5^{\circ} \mathrm{C}$. Incident solar radiation was measured by Pyranometer (TBQ-2, Jinzhou Sunshine, China) with an error of $\pm 2 \%$. A deflecting vane anemometer (Jinzhou Sunshine, China) was used to measure ambient wind speed. The air mass flow rate was measured by a gas mass flow meter with a maximum permissible error of $\pm 1 \%$. All the measured values were recorded by Agilent 34970A data acquisition unit at an interval of 30 seconds.

2.3. Evaluation of the Thermal Performance of DFSC. In air heating, the instantaneous thermal efficiency of the collector is defined as the thermal energy increase of air flow through the collector divided by the received solar irradiance, expressed as

$$
\eta_{a}=\frac{\dot{m} C_{a}\left(T_{\text {out }}-T_{\text {in }}\right)}{S A_{c}} .
$$

In water heating, the daily thermal efficiency of the collector is defined as the thermal energy increase of water in the tank divided by the daily solar irradiation on the plane of the collector during the experiment time from early morning till late afternoon, expressed as

$$
\eta_{w}=\frac{M C_{w}\left(T_{\text {final }}-T_{\text {inital }}\right)}{G A_{c}},
$$

where $M$ is the total mass of water in the system.

A semiempirical system efficiency correlated with the daily efficiency data is adopted to evaluate the thermal performance of DFSC thermosiphon system [15]:

$$
\eta_{w}=\alpha^{\prime}-U \frac{T_{\text {inital }}-\overline{T_{a}}}{G},
$$

where $\alpha^{\prime}$ and $U$ are the parameters depending on the properties of the solar thermosiphon system. $\alpha^{\prime}$ can be interpreted as the system efficiency, and it means the system efficiency under the condition in which the initial temperature equals the mean ambient temperature. $U$ is the energy loss coefficient of the collector. $\alpha^{\prime}$ and $U$ can be determined from linear regression analysis of the daily efficiency of DFSC system from experimental results. 


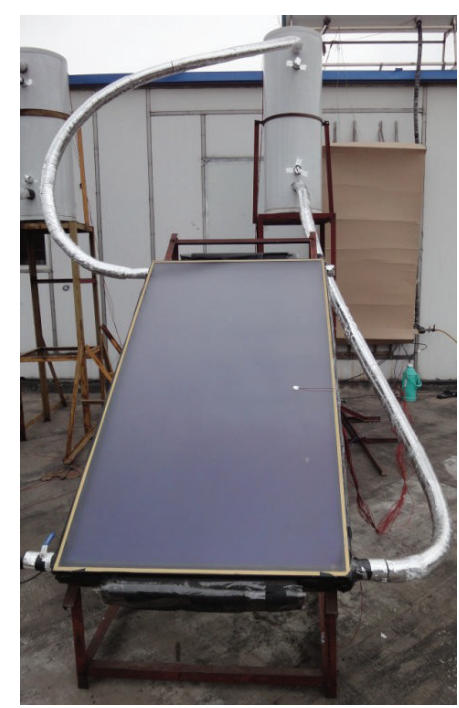

(a) Photograph

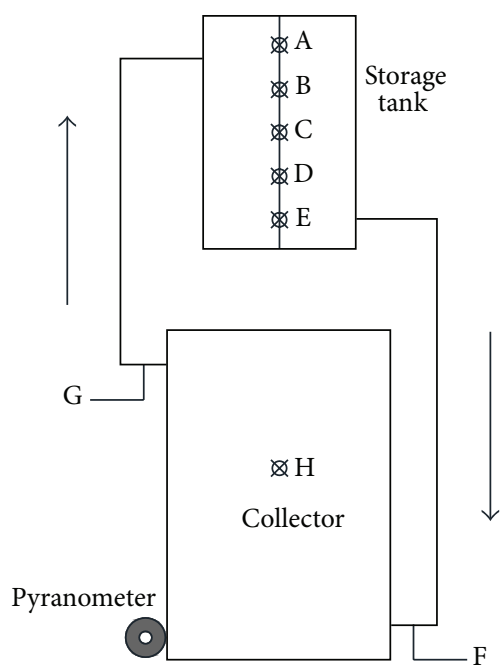

A, B, C, D, E, F, G, H: thermometer

(b) Schematic

FIGURE 2: Configuration of the experimental setup of water heating test system.

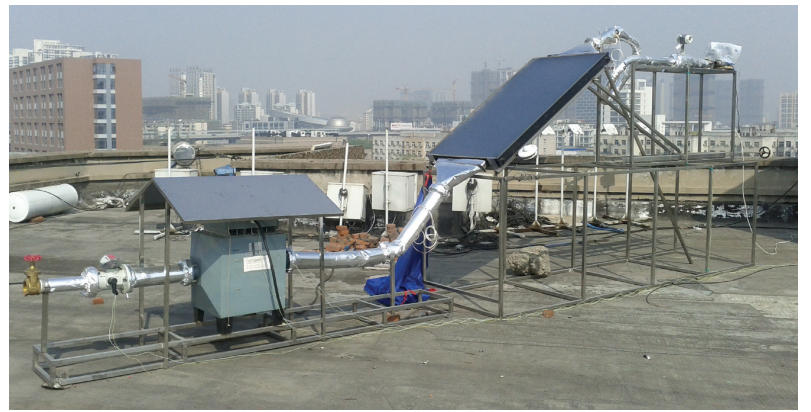

(a) Photograph

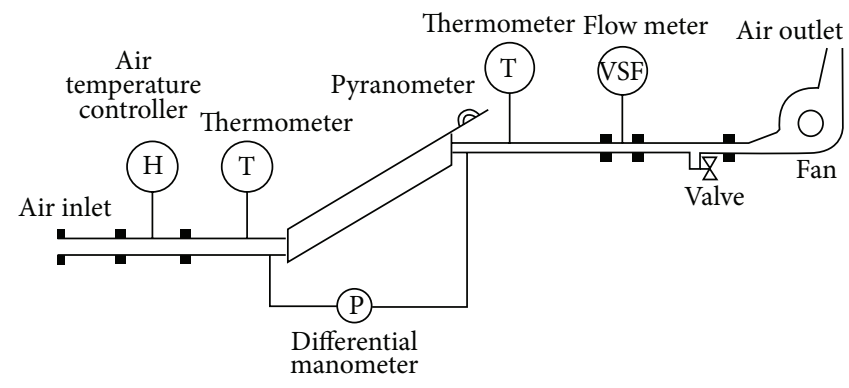

(b) Schematic

FIgURE 3: Configuration of the experimental setup of air heating test system.

\section{Numerical Modelling}

3.1. Modelling of the Collector in Air Heating Mode. The numerical model of air heating has been established in our previous work [4]. The essential components of the collector are the glass cover, the backboard, and the absorber plate. Under the assumption that the temperatures of the glass cover, absorber, and the back plate vary only in the direction of air flow, the energy balance equations of steady-state conditions were established. The temperature of the air streams can be obtained by solving the energy equations. Then the useful heat gain and efficiency of the collector can be obtained.

\subsection{Modelling of the Collector in Water Heating Mode}

3.2.1. Governing Equations. The scheme of heat transfer of the components of the collector in water heating mode is shown in Figure 4. Since water in the tubes flows along the length of the collector, the temperature difference on the components occurs mainly in the length direction, except that on the absorber plate, where solar heat is also conducted in the width

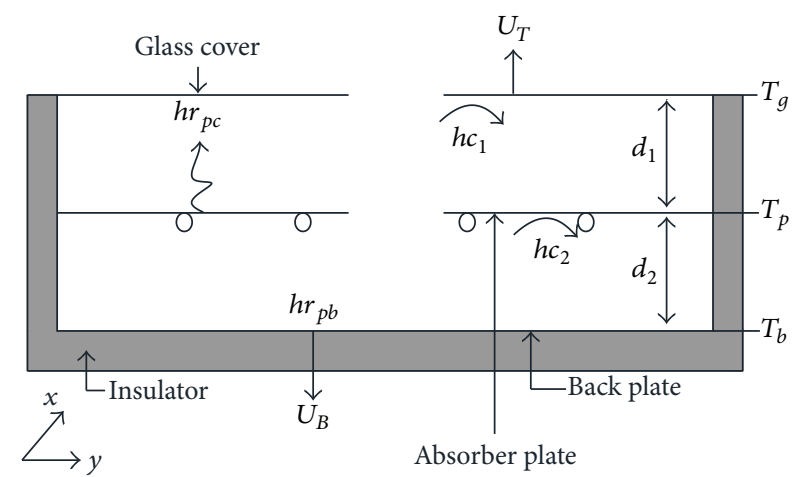

FIGURE 4: Heat transfer of components of the collector.

direction to water tubes. In the following, energy balance equations are given for the components of DFSC including the glass cover, absorber plate, copper tubes, backboard, and the water flow in tubes. 
The energy equation of the glass cover is one dimensional in the length direction ( $x$-direction):

$$
\begin{aligned}
\rho_{g} C_{g} d_{g} \frac{\partial T_{g}}{\partial t}= & k_{g} d_{g} \frac{\partial^{2} T_{g}}{\partial x^{2}} \\
& +\left(h c_{p-g}+h r_{p-g}\right)\left(T_{p}-T_{g}\right) \\
& +h w\left(T_{a}-T_{g}\right)+h r_{s}\left(T_{s}-T_{g}\right)+\alpha_{g} S .
\end{aligned}
$$

The energy equation of absorber plate is two dimensional in both length and width direction as

$$
\begin{aligned}
\rho_{p} C_{p} d_{p} \frac{\partial T_{p}}{\partial t}= & k_{p} d_{p} \frac{\partial^{2} T_{p}}{\partial x^{2}}+k_{p} d_{p} \frac{\partial^{2} T_{p}}{\partial y^{2}} \\
& -\left(h c_{p-g}+h r_{p-g}\right)\left(T_{p}-T_{g}\right) \\
& -h c_{p-b}\left(T_{p}-T_{b}\right)-Q_{c, p t}-Q_{p} \\
& +\alpha_{p} \tau_{g} S
\end{aligned}
$$

where $Q_{p}$ is the irradiative heat from absorber plate to copper tube and interior plate of backboard and $Q_{c, p t}$ is the heat conducted from absorber plate to water tube:

$$
Q_{c, p t}=0
$$

where the absorber plate is not connected with the tube, and

$$
Q_{c, p t}=\frac{\left(T_{p}-T_{t}\right)}{\left(R_{p-t} \cdot A_{p i}\right)},
$$

where the absorber plate is connected with the tube, and $A_{p i}$ is the area of the control volume of the absorber plate, $A_{p i}=$ $d x \cdot d y$.

The one-dimensional heat balance equation of the copper tube is given as

$$
\begin{aligned}
\pi\left(D_{t}-d_{t}\right) d_{t} \rho_{t} C_{t} \frac{\partial T_{t}}{\partial t} \\
=\pi\left(D_{t}-d_{t}\right) d_{t} k_{t} \frac{\partial^{2} T_{t}}{\partial x^{2}}+P_{t} h c_{w-t}\left(T_{w}-T_{t}\right) \\
\quad+\pi D_{t} h c_{t-b}\left(T_{b}-T_{t}\right)+\frac{1}{R_{p-t}}\left(T_{p}-T_{t}\right)-\pi D_{t} Q_{t},
\end{aligned}
$$

where $Q_{t}$ is the irradiative heat from copper tube to absorber plate and the interior plate of backboard.

The energy equation of the interior plate of backboard is given as

$$
\begin{aligned}
\rho_{b} C_{b} d_{b} \frac{\partial T_{b}}{\partial t}= & k_{b} d_{b} \frac{\partial^{2} T_{b}}{\partial x^{2}}+h c_{p-b}\left(T_{p}-T_{b}\right) \\
& +\frac{N \pi D_{t}}{w_{b}} h c_{t-b}\left(T_{t}-T_{b}\right)+U_{b}^{\prime}\left(T_{a}-T_{b}\right) \\
& -Q_{b}
\end{aligned}
$$

where $U_{b}^{\prime}=1 /\left(d_{R} / k_{R}+1 / h w\right)$ and $Q_{b}$ is the irradiative heat from interior plate of backboard to copper tube and absorber plate. The calculation method of $Q_{p}, Q_{t}$, and $Q_{b}$ is described in Section 3.2.3.

Equation of the water flow in copper tubes is given as

$$
\begin{aligned}
A_{t} \rho_{w} C_{w} \frac{\partial T_{w}}{\partial t}= & -A_{t} \rho_{w} u_{w} C_{w} \frac{\partial T_{w}}{\partial x}+A_{t} k_{w} \frac{\partial^{2} T_{w}}{\partial x^{2}} \\
& +P_{t} h c_{w-t}\left(T_{t}-T_{w}\right),
\end{aligned}
$$

where $A_{t}$ is the area of the internal cross section of the tube.

The water flow rate in the tubes is determined by the interaction between the buoyant head $H_{T}$ due to thermosiphon effect and the friction loss $H_{f}$ in the water flow loop of the thermosiphon system [16]. The buoyant head $H_{T}$ can be expressed as a function of the specific gravity of water which is the function of temperature, and the friction loss $H_{f}$ can be expressed as a function of water flow rate. So the flow rate can be determined by equating $H_{T}$ and $H_{f}$ and solving the energy balance and flow equations iteratively.

3.2.2. Heat Transfer Coefficients. The convective heat transfer coefficient on exterior surface of the collector is calculated by

$$
h w=2.8+3.0 \mathrm{~V}
$$

(see [17]).

The irradiative heat transfer coefficient on exterior surface of the glass cover is estimated by

$$
h r_{s}=\varepsilon_{g} \sigma\left(T_{g}^{2}+T_{s}^{2}\right)\left(T_{g}+T_{s}\right),
$$

where $T_{s}=0.0552 T_{a}^{1.5}[18]$.

The irradiative heat transfer coefficient between the glass cover and the absorber plate is estimated by

$$
h r_{p-g}=\frac{\sigma\left(T_{p}^{2}+T_{g}^{2}\right)\left(T_{p}+T_{g}\right)}{\left(1 / \varepsilon_{p}+1 / \varepsilon_{g}-1\right)} .
$$

The natural convective heat transfer coefficients in the two void channels are obtained by introducing Nusselt number as

$$
h \mathrm{c}=\frac{\mathrm{Nu} k}{d} .
$$

The Nusselt numbers for the upper and lower channels are calculated by

$$
\begin{aligned}
& \mathrm{Nu}_{\text {up }} \\
& =1 \\
& \quad+1.44\left[1-\frac{1708}{\mathrm{Ra}_{L} \cos \theta}\right]^{*}\left[1-\frac{1708(\sin 1.8 \theta)^{1.6}}{\mathrm{Ra}_{L} \cos \theta}\right] \\
& \quad+\left[\left(\frac{\mathrm{Ra}_{L} \cos \theta}{5830}\right)^{1 / 3}-1\right]^{*} ; \\
& \mathrm{Nu}_{\text {low }}=1+\left[0.364 \frac{L_{p}}{d_{\text {low }}} \mathrm{Ra}_{L}^{1 / 4}-1\right] \sin \theta
\end{aligned}
$$


(see $[19,20]$, resp.), where $\theta$ is the tilt angle of the collector from the horizontal plane. The test rigs are mounted in Hefei $\left(32^{\circ} \mathrm{N}, 117^{\circ} \mathrm{E}\right)$ and the tilted angle of the collectors is fixed at $35^{\circ}$.

3.2.3. Numerical Approaches. Finite difference method is applied to discretize the above energy equations by time and space. For the one-dimensional energy equations of the glass cover, copper tube, bottom plate, and water in the copper tube, space discretization is in the length direction. For the two-dimensional energy equation of the absorber plate, since thermal field of the absorber plate is periodic in the width direction and symmetric about the water tube, the energy equation of absorber plate is solved for only half width of the absorber plate between the water tubes, with symmetric boundary conditions on two sides in $y$-direction. The space discretization of the absorber plate is shown in Figure 5. Boundary conditions in $x$-direction of the glass cover, copper tube, bottom plate, and absorber plate are decided to be adiabatic boundary conditions. The boundary conditions of absorber plate in $y$-direction are

$$
\begin{aligned}
-\left.k_{p} \frac{\partial T_{p}}{\partial y}\right|_{y=0} & =0, \\
\left.Q_{c, p t}\right|_{y=0} & =0, \\
-\left.k_{p} \frac{\partial T_{p}}{\partial y}\right|_{y=L_{1,1}} & =0, \\
\left.Q_{c, p t}\right|_{y=L_{1,1}} & =\frac{\left(T_{p}-T_{t}\right)}{\left(R_{p-t} \cdot A_{p i}\right)} .
\end{aligned}
$$

The irradiative heat transfer relationship between the grid nodes of absorber plate, interior surface of the backboard, and tube is shown in Figure 6. $Q_{p, i j}, Q_{t, i}$, and $Q_{b, i}$ corresponding to the irradiative heat transfer items in the discrete differential forms of (5), (8), and (9), respectively, are obtained by solving irradiation equation set of the irradiation energy transfer net of Figure 6.

The view factors can be obtained by [19]

$$
\begin{aligned}
F_{b-t}= & 1-\left[1-\frac{D_{t}^{2}}{W^{2}}\right]^{1 / 2} \\
& +\frac{D_{t}}{W} \tan ^{-1}\left\{\left[\frac{W^{2}-D_{t}^{2}}{D_{t}^{2}}\right]^{1 / 2}\right\}, \\
F_{j-t}= & \frac{D_{t}}{2\left(L_{j, 1}-L_{j, 2}\right)}\left[\tan ^{-1} \frac{2 L_{j, 1}}{D_{t}}-\tan ^{-1} \frac{2 L_{j, 2}}{D_{t}}\right],
\end{aligned}
$$

where $D_{t}$ stands for diameter of copper tubes, $W$ stands for distance between every two adjacent copper tubes, and $L_{j, 1}$ and $L_{j, 2}$ stand for distances from the tube center to the two grid edges of $j$ node in the $y$-direction, respectively, as shown in Figure 5.

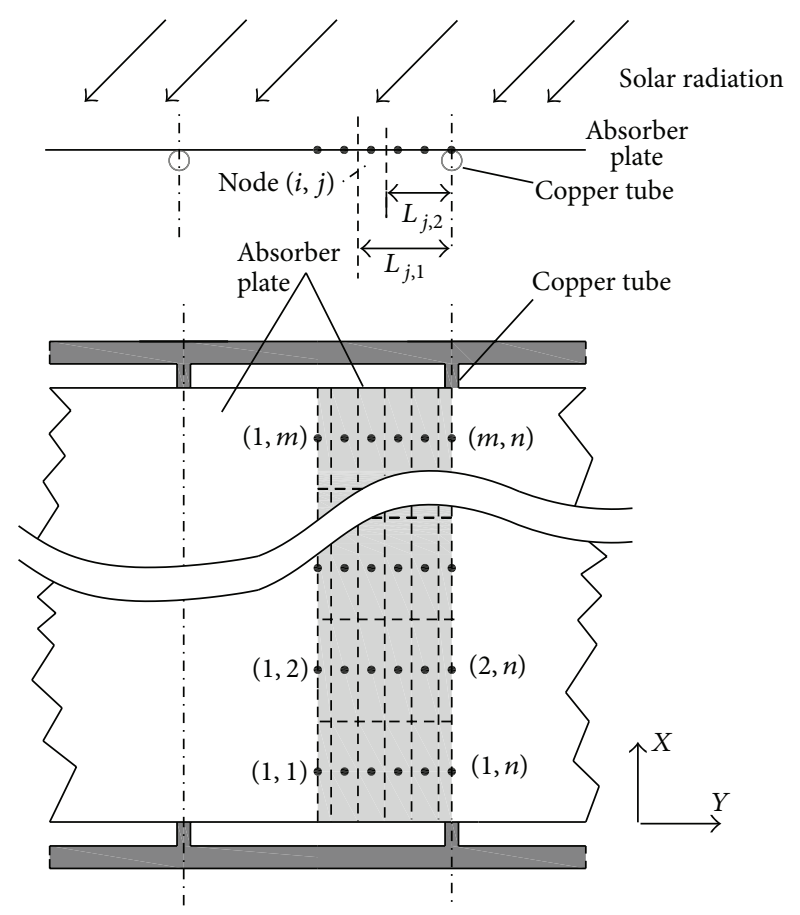

FIGURE 5: Differential grid partition of the absorber plate.

TABLE 1: Thermal properties of the materials in the collector.

\begin{tabular}{lccc}
\hline Parameters & Values & Parameters & Values \\
\hline$\alpha_{p}$ & 0.95 & $k_{w}$ & $0.628 \mathrm{~W} /(\mathrm{m} \cdot \mathrm{K})$ \\
$\varepsilon_{p}$ & 0.05 & $k_{R}$ & $0.046 \mathrm{~W} /(\mathrm{m} \cdot \mathrm{K})$ \\
$\varepsilon_{p 2}$ & 0.9 & $k_{g}$ & $1.05 \mathrm{~W} /(\mathrm{m} \cdot \mathrm{K})$ \\
$\tau_{g}$ & 0.912 & $k_{b}$ & $80 \mathrm{~W} /(\mathrm{m} \cdot \mathrm{K})$ \\
$\varepsilon_{g}$ & 0.9 & $k_{t}$ & $393 \mathrm{~W} /(\mathrm{m} \cdot \mathrm{K})$ \\
$\alpha_{g}$ & 0.038 & $k_{p}$ & $237 \mathrm{~W} /(\mathrm{m} \cdot \mathrm{K})$ \\
$\varepsilon_{t}$ & 0.9 & $\rho_{g}$ & $2500 \mathrm{~kg} / \mathrm{m}^{3}$ \\
$\varepsilon_{b}$ & 0.9 & $\rho_{p}$ & $2720 \mathrm{~kg} / \mathrm{m}^{3}$ \\
$C_{g}$ & $750 \mathrm{~J} /(\mathrm{kg} \cdot \mathrm{K})$ & $\rho_{t}$ & $8933 \mathrm{~kg} / \mathrm{m}^{3}$ \\
$C_{p}$ & $933 \mathrm{~J} /(\mathrm{kg} \cdot \mathrm{K})$ & $\rho_{b}$ & $7800 \mathrm{~kg} / \mathrm{m}^{3}$ \\
$C_{t}$ & $397 \mathrm{~J} /(\mathrm{kg} \cdot \mathrm{K})$ & $C_{b}$ & $460 \mathrm{~J} /(\mathrm{kg} \cdot \mathrm{K})$ \\
\hline
\end{tabular}

As a result of finite difference method, the energy equations (5)-(10) are transformed into algebraic equations, which are solved by iteration method. In the solution procedure, the initial condition and the instantaneous boundary conditions, such as solar radiation and ambient temperature, are set based on the experimental data.

3.3. Model Validation. The results of the numerical simulation of DFSC in water and air heating modes are compared with the experimental results in the following. Thermal properties of materials in the collector are listed in Table 1. As shown in Figure 7, the simulation results of temperatures of absorber plate, copper tubes, and glass cover are in good agreement with the experimental results in water heating mode. Temperatures in water tank from numerical results are compared with the experimental data as shown in Figure 8. 


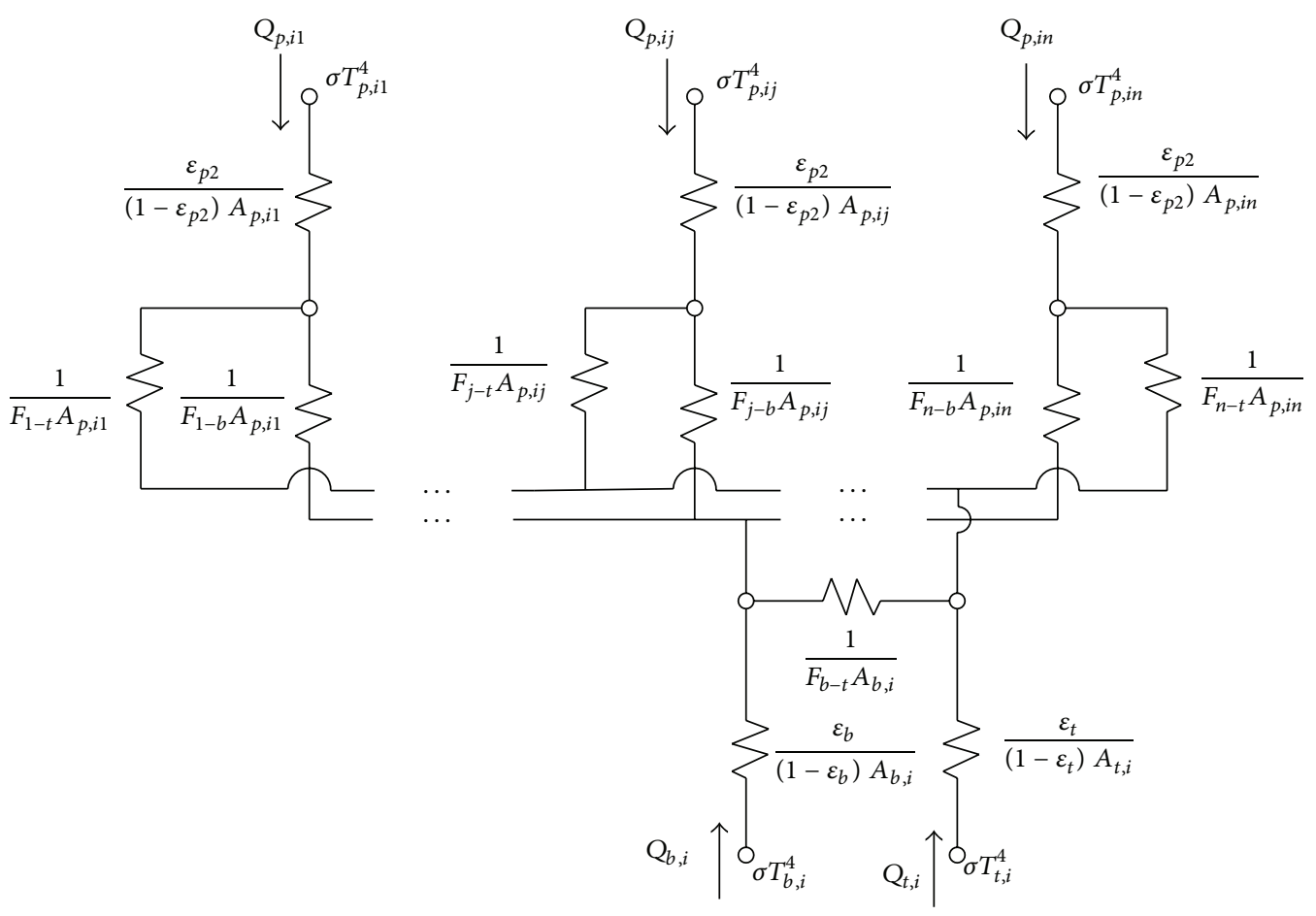

FIGURE 6: Irradiative heat transfer network diagram of the grid nodes.

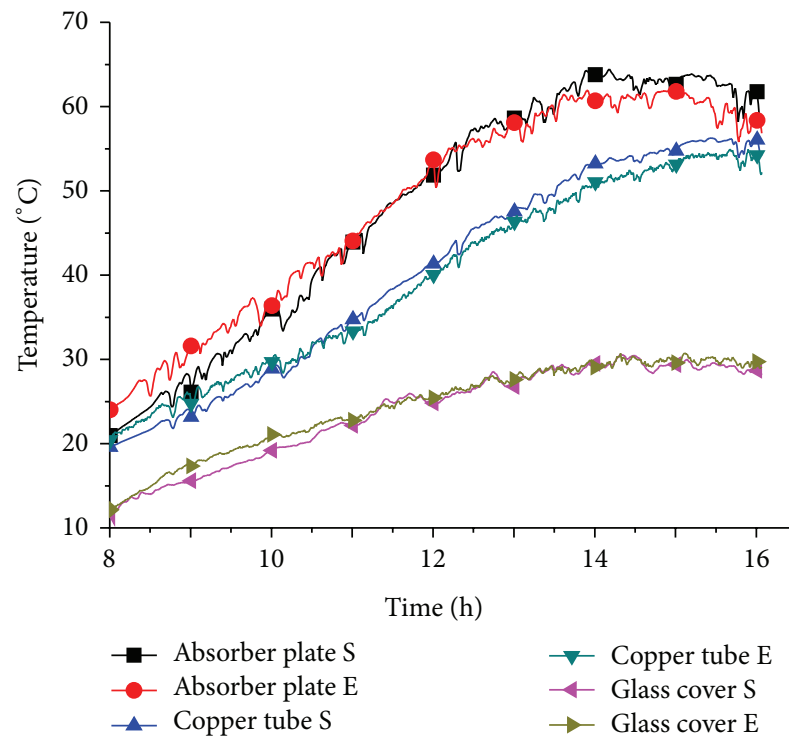

FIGURE 7: Variation of the temperatures in the collector with time (E: experimental results; S: numerical results).

The average temperature of water in the tank from numerical results is within a deviation of $1.3^{\circ} \mathrm{C}$ from the experimental data. The daily thermal efficiency based on (2) is $60.8 \%$ and $58.8 \%$ from experimental and numerical results, respectively. The relative deviation of the efficiency is $3.2 \%$. Instantaneous efficiency of the collector in air heating mode from numerical results and experimental results are compared in Table 2. It is shown that the numerical model can give good prediction.

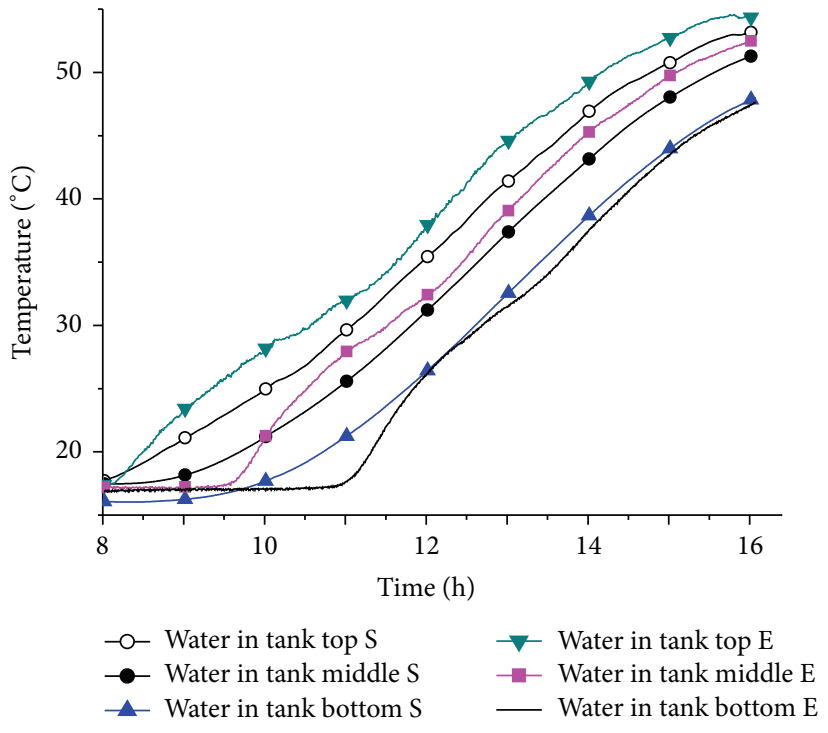

FIGURE 8: Variation of the water temperatures in the tank with time (E: experimental results; S: numerical results).

TABLE 2: Air heating efficiency of the collector under different operating conditions (E: experimental; S: numerical).

\begin{tabular}{cccccccc}
\hline Date & $\begin{array}{c}\dot{m} \\
(\mathrm{~kg} / \mathrm{s})\end{array}$ & $\begin{array}{c}T_{a} \\
\left({ }^{\circ} \mathrm{C}\right)\end{array}$ & $\begin{array}{c}T_{\text {out }} \\
\left({ }^{\circ} \mathrm{C}\right)\end{array}$ & $\begin{array}{c}S \\
\left(\mathrm{~W} / \mathrm{m}^{2}\right)\end{array}$ & $\begin{array}{c}\eta_{a, E} \\
(\%)\end{array}$ & $\begin{array}{c}\eta_{a, S} \\
(\%)\end{array}$ & $\begin{array}{c}\delta_{\eta_{a}} \\
(\%)\end{array}$ \\
\hline $06 / 21$ & 0.027 & 33.0 & 56.5 & 751.8 & 55.6 & 55.9 & 7.27 \\
$06 / 20$ & 0.04 & 31.9 & 50.3 & 818.7 & 60.2 & 61.7 & 8.49 \\
\hline
\end{tabular}


TABLE 3: Water heating efficiency of the collector in different days.

\begin{tabular}{|c|c|c|c|c|c|c|c|}
\hline Date & $\overline{T_{a}}\left({ }^{\circ} \mathrm{C}\right)$ & $T_{\text {inital }}\left({ }^{\circ} \mathrm{C}\right)$ & $T_{\text {final }}\left({ }^{\circ} \mathrm{C}\right)$ & $\Delta T\left({ }^{\circ} \mathrm{C}\right)$ & $G\left(\mathrm{MJ} / \mathrm{m}^{2}\right.$ day $)$ & $\eta_{w}(\%)$ & $\delta_{\eta_{w}}(\%)$ \\
\hline $03 / 31$ & 18.5 & 13.0 & 55.2 & 42.2 & 24.3 & 58.2 & 4.37 \\
\hline 04/01 & 26.5 & 28.5 & 58.1 & 29.7 & 18.0 & 55.2 & 5.37 \\
\hline $04 / 07$ & 22.2 & 17.2 & 51.9 & 34.7 & 19.2 & 60.8 & 4.88 \\
\hline $04 / 26$ & 24.2 & 17.1 & 57.7 & 40.6 & 22.8 & 59.7 & 4.46 \\
\hline $05 / 09$ & 26.4 & 22.6 & 43.0 & 20.4 & 11.3 & 60.6 & 6.90 \\
\hline $05 / 10$ & 27.4 & 23.0 & 58.8 & 35.8 & 20.9 & 57.5 & 4.79 \\
\hline 05/11 & 28.4 & 28.4 & 58.6 & 30.2 & 17.7 & 57.3 & 5.31 \\
\hline $05 / 16$ & 30.3 & 32.6 & 60.3 & 27.7 & 16.6 & 56.0 & 5.61 \\
\hline $05 / 21$ & 21.8 & 17.8 & 54.7 & 36.9 & 21.2 & 58.3 & 4.71 \\
\hline $06 / 02$ & 27.4 & 28.0 & 52.3 & 24.4 & 14.5 & 56.4 & 6.10 \\
\hline $06 / 08$ & 32.6 & 25.7 & 57.3 & 31.7 & 17.3 & 61.4 & 5.15 \\
\hline $06 / 12$ & 31.9 & 26.4 & 55.5 & 29.1 & 16.3 & 60.0 & 5.44 \\
\hline
\end{tabular}

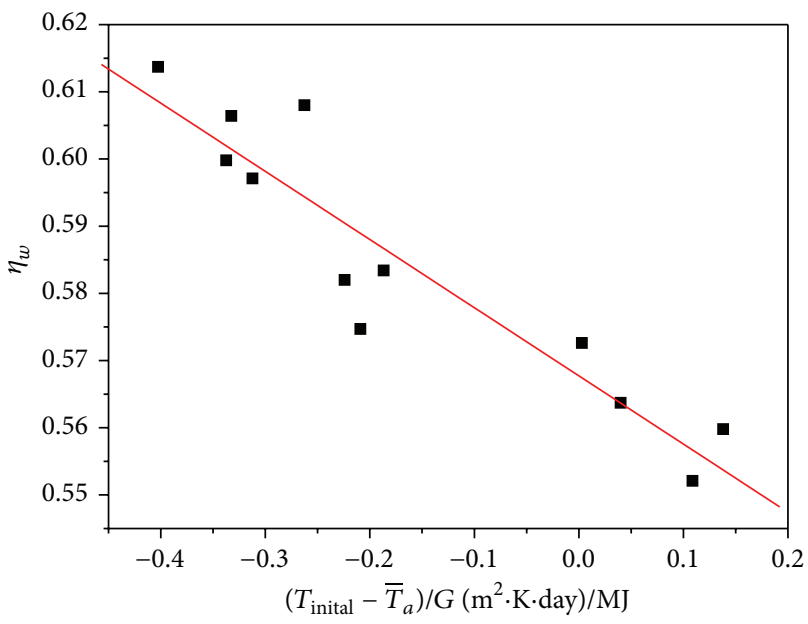

FIGURE 9: Graphical plot of test results of the water heating thermal efficiency.

\section{Results and Discussion}

4.1. Thermal Performance of DFSC in the Experiment. The test results of air heating experiment with different mass flow rate are listed in Table 2 . The efficiency varied with the flow rate and reached $60.2 \%$ under the mass flow rate of $0.04 \mathrm{~kg} / \mathrm{s}$.

Thermal efficiency of the DFSC water heating system is shown in Table 3. With different inlet water temperature and environment condition, the daily efficiency of the system ranges from $55.2 \%$ to $61.4 \%$. The efficiency can be obtained by linear regression analysis of the daily efficiency from experiment results, as shown in Figure 9. Values of $\alpha^{\prime}$ and $U$ equal 0.568 and 0.101 , respectively, and with a correlation coefficient of -0.93 , the semiempirical expression (3) is in good agreement with the experimental data. So $\eta_{w}$ is expressed as

$$
\eta_{w}=0.568-0.101 \frac{T_{\mathrm{inital}}-\overline{T_{a}}}{G} .
$$

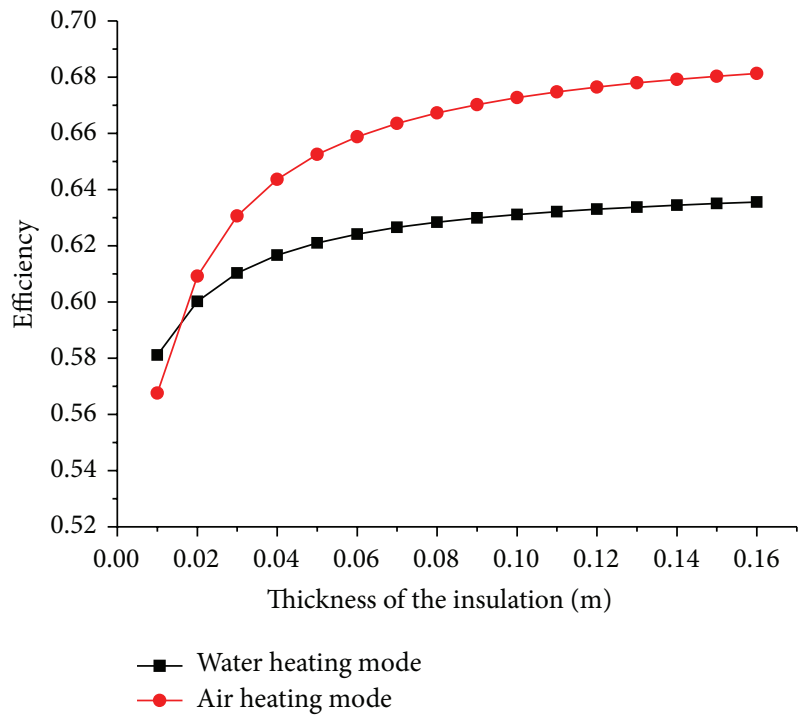

FIGURE 10: Effect of insulation thickness on efficiency of the collector in two working modes.

4.2. Effect of Different Inner Parameters. The numerical simulations are performed to investigate the effect of inner parameters including thickness of insulation, depths of upper and lower air channels, and diameter and number of copper tubes on efficiency of the collector in the two working modes. In the simulation of air heating, incident solar radiation, ambient air temperature, and air flow rate are set as $800 \mathrm{~W} / \mathrm{m}^{2}, 20^{\circ} \mathrm{C}$, and $0.03 \mathrm{~kg} / \mathrm{s}$, respectively. In the simulation of water heating, environment data of $04 / 07$ is used, and the thermosiphon system of DFSC is evaluated during the period from 8:00 a.m. till 16:00 p.m.

Figure 10 shows the variation of efficiency of the collector with insulating thickness. Thicker insulation layer results in higher efficiency in both air heating and water heating modes. However, as the thickness increases to $0.06 \mathrm{~m}$, the efficiency increasing tendency becomes nearly flat.

Figures 11 and 12 show the influence of depths of air channels on daily efficiency of the water heating system with 


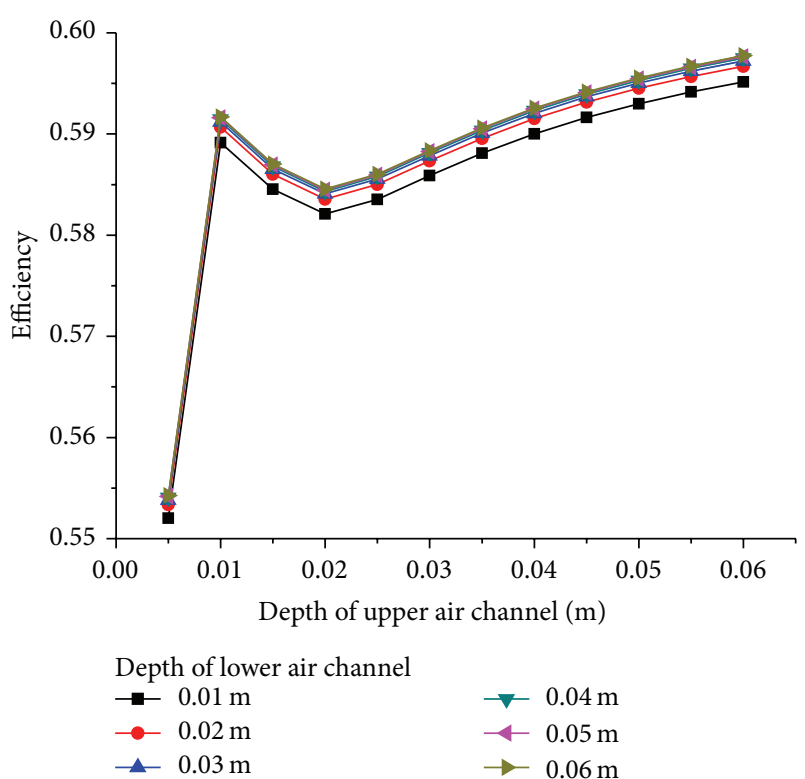

FIGURE 11: Effect of depths of air channels on efficiency of the collector in water heating mode ( $0.015 \mathrm{~m}$ thick insulation).

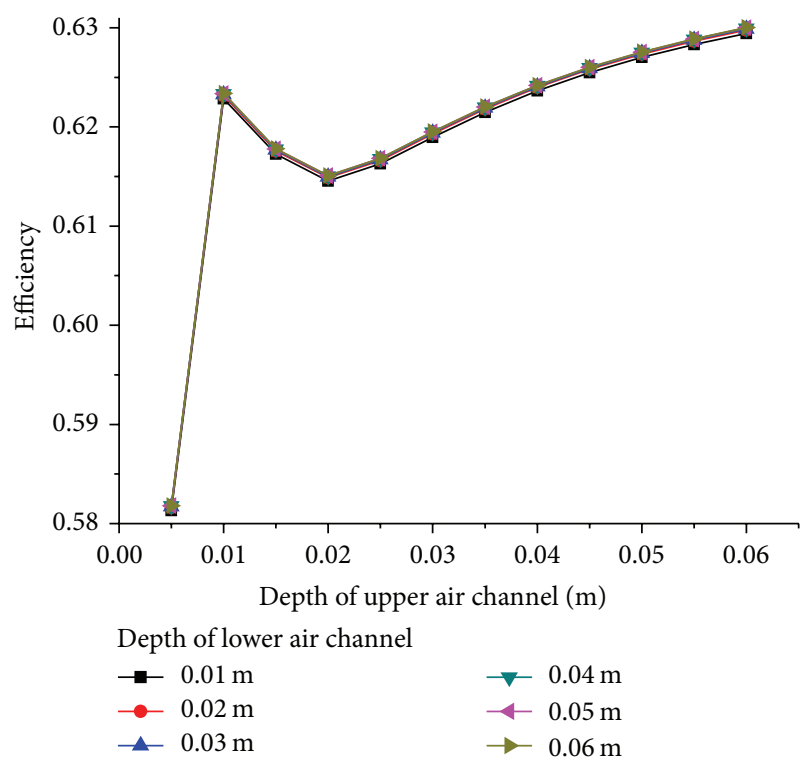

FIGURE 12: Effect of depths of air channels on efficiency of the collector in water heating mode ( $0.06 \mathrm{~m}$ thick insulation).

the insulation thickness of $0.015 \mathrm{~m}$ and $0.06 \mathrm{~m}$, respectively. Although the variation tendency of the efficiency is almost the same for different insulation thicknesses, it is about 3\% higher with the thicker insulation of $0.06 \mathrm{~m}$. The efficiency is not sensitive to the depth of lower channel, especially while the back insulation is as thick as $0.06 \mathrm{~m}$. While the back insulation is as thin as $0.015 \mathrm{~m}$, the increase of the lower channel till $0.02 \mathrm{~m}$ results in higher efficiency. However the depth of upper channel shows strong influence on the efficiency. At least $0.01 \mathrm{~m}$ is required to avoid conduction heat loss. The depth of $0.01 \mathrm{~m}$ is a critical value above which

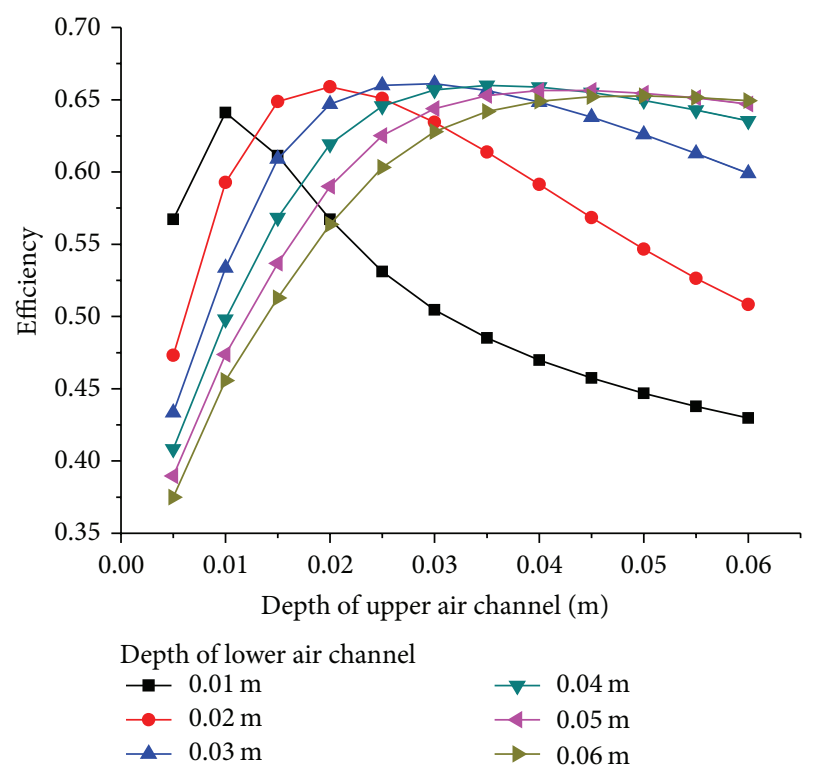

FIGURE 13: Effect of depths of air channels on the efficiency of the collector in air heating mode with the insulation thickness of $0.06 \mathrm{~m}$.

the natural convection begins to occur in the channel, which leads to the increase of heat loss via glazing and decrease of the efficiency. Hence the efficiency at $0.01 \mathrm{~m}$ is unstable. The efficiency begins to increase again with the increase of the depth that is greater than $0.02 \mathrm{~m}$. The simulation results are consistent with the experimental results of solar water heater from [21], where the distance of $0.06 \mathrm{~m}$ between the absorber plate and the glass cover has been suggested. Compared with the traditional flat-plate solar water heater, there is a lower air channel except for the upper channel in DFSC, so the consumption of materials must be considered for the large thickness of DFSC. Moreover, when the depth of upper channel is larger than $0.04 \mathrm{~m}$, the efficiency increases more and more slowly, so the size of $0.04 \mathrm{~m}$ is suggested as the depth of upper channel.

In air heating mode, efficiency of the collector is sensitive to the depths of both channels, as shown in Figure 13. At a fixed depth of lower channel, the efficiency increases with the depth of upper channel to a maximum and then begins to decrease. The maximum efficiency occurs near the point where the depths of the two channels are equal. While the depth of the lower channel is greater than $0.03 \mathrm{~m}$, the decrease of efficiency after the maximum value with the increase of the depth of upper channel becomes slower. The highest efficiency is obtained when the upper and lower air channels are both around $0.03 \mathrm{~m}$ depth. The depth of both channels of $0.03-0.04 \mathrm{~m}$ is also suited to pursue efficiency in water heating mode.

Influence of the diameter and number of the copper tubes on efficiency of the two working modes is investigated on condition that the thickness of back insulation is set as $0.06 \mathrm{~m}$ and the depths of two air channels are set as $0.04 \mathrm{~m}$. Influence of the diameter is shown in Figure 14; the number of tubes was set to be 8 in the calculation. Variation of 


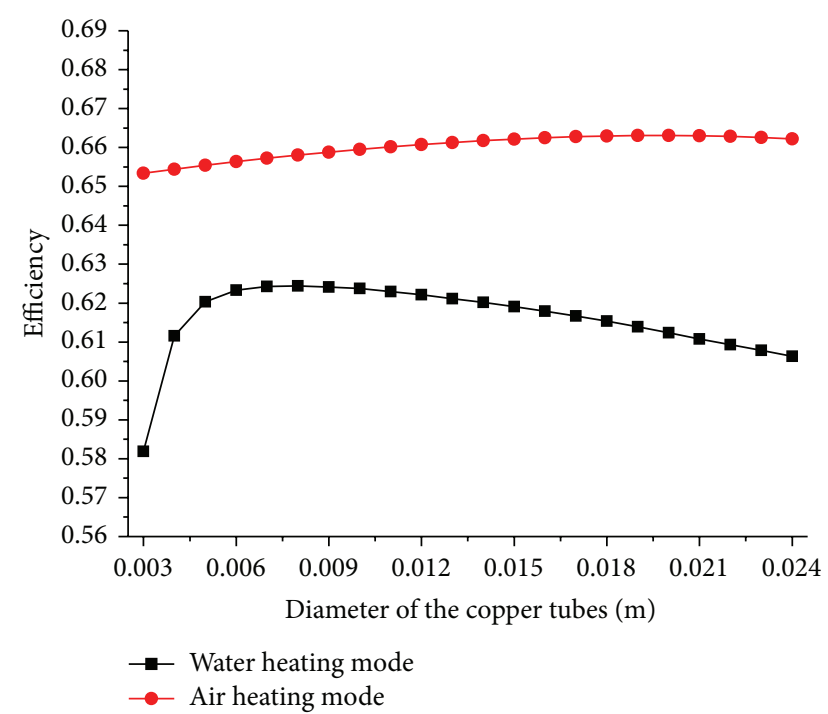

FIGURE 14: Effect of the diameter of copper tubes on efficiency of the collector in two working modes.

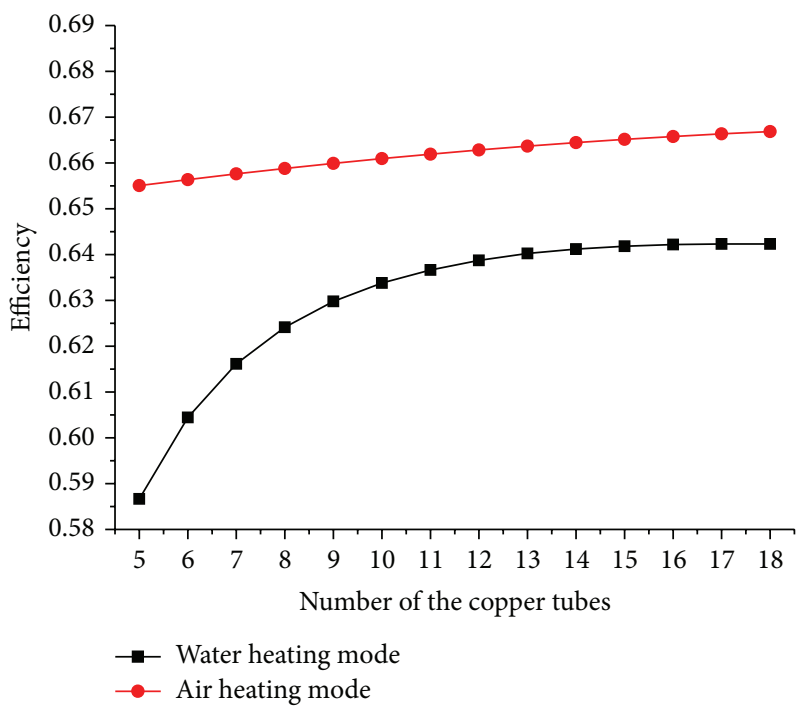

FIGURE 15: Effect of the number of copper tubes on efficiency of the collector in two working modes.

efficiency with the rise of the inner diameter of the tubes is different in the two working modes. In air heating mode, the efficiency increases modestly with the diameter rise, although the tubes have extended the heat transfer area between the absorber plate and flowing air like fins. In water heating mode, the efficiency change is steeper and has a maximum value when the diameter of copper tubes is $0.008 \mathrm{~m}$. With the fixed diameter, influence of quantity of copper tubes was investigated, as shown in Figure 15. The increasing number of tubes improves the efficiency slightly in air heating mode, but noticeably in water heating mode until the number is greater than 8. Hence for DFSC, only the effect on water heating mode needs to be considered while choosing the diameter and number of tubes.

\section{Conclusions}

In order to investigate the thermal performance of flat DFSC and the effect of inner parameters of the collector, experiment apparatus was set up, and a dynamic numerical model to simulate the solar heating system has been established. The experimental results show that the daily efficiency of the thermosiphon system of DFSC in water heating is more than $55 \%$, and the instantaneous efficiency of DFSC in air heating can reach $60.2 \%$. The numerical results show well consistency with the experimental results.

The influence of the insulation thickness, the depths of the upper and lower air channels, and the diameter and the number of water tubes on the thermal efficiency of DFSC in water/air heating modes has been analyzed by numerical simulation. It is shown that the back insulation needs to be as thick as $0.06 \mathrm{~m}$ to prevent heat loss via backboard, and the equal depth of upper and lower channel of $0.03-0.04 \mathrm{~m}$ is not only optimal for DFSC in air heating but also suited in water heating mode. The diameter and the number of water tubes show slight effect on the efficiency of DFSC in air heating but show prominent effect in water heating mode. Hence only water heating mode needs to be taken into account while considering the arrangement of water tubes in DFSC.

\section{Nomenclature}

A: $\quad$ Area, $\mathrm{m}^{2}$

$A_{c}:$ Collector aperture area, $\mathrm{m}^{2}$

C: $\quad$ Specific heat capacity, $\mathrm{J} /(\mathrm{kg} \cdot \mathrm{K})$

$d$ : Thickness or depth, $\mathrm{m}$

$D_{t}$ : $\quad$ Outer diameter of the tube, $\mathrm{m}$

F: View factor

G: Daily solar irradiation on the plane of the collector, $\mathrm{MJ} /\left(\mathrm{m}^{2}\right.$ day $)$

$h c$ : Convective heat transfer coefficient, $\mathrm{W} /\left(\mathrm{m}^{2} \mathrm{~K}\right)$

$h w$ : Convective heat transfer coefficient with the ambient, $\mathrm{W} /\left(\mathrm{m}^{2} \mathrm{~K}\right)$

$h r: \quad$ Radiative heat transfer, $\mathrm{W} /\left(\mathrm{m}^{2} \mathrm{~K}\right)$

$k: \quad$ Thermal conductivity, $\mathrm{W} /(\mathrm{m} \cdot \mathrm{K})$

$L$ : Length, $m$

$m$ : Number of nodes in $x$-direction

$\dot{m}: \quad$ Mass flow rate of air in air heating, $\mathrm{kg} / \mathrm{s}$

$M$ : Mass of water in water heating system, $\mathrm{kg}$

$n: \quad$ Number of nodes in $y$-direction

$N$ : Number of copper tubes

$\mathrm{Nu}$ : Nusselt number

$P_{t}: \quad$ Inner perimeter of the tube, $\mathrm{m}$

$Q: \quad$ Irradiative heat flux, $\mathrm{W} / \mathrm{m}^{2}$

$Q_{c}$ : Conductive heat flux, $\mathrm{W} / \mathrm{m}^{2}$

$R: \quad$ Total thermal resistance, $\mathrm{K} / \mathrm{W}$

$\mathrm{Ra}_{L}$ : Rayleigh number

$S: \quad$ Solar irradiance on the plane of the collector, $\mathrm{W} / \mathrm{m}^{2}$

$t: \quad$ Time, $\mathrm{s}$

$T: \quad$ Temperature, $\mathrm{K}$

$\overline{T_{a}}$ : Daily average ambient air temperature, $\mathrm{K}$ 
$T_{\text {inital }}$ : Initial water temperature in storage tank, K

$T_{\text {final }}$ : Final water temperature in storage tank, $\mathrm{K}$

$U$ : Coefficient of overall system heat-loss rate, $\mathrm{MJ} /\left(\mathrm{m}^{2} \mathrm{~K}\right.$ day $)$

$U^{\prime}: \quad$ Heat-loss rate, $\mathrm{W} /\left(\mathrm{m}^{2} \mathrm{~K}\right)$

$V: \quad$ Velocity of ambient wind, $\mathrm{m} / \mathrm{s}$

$w: \quad$ Width, $\mathrm{m}$

$W: \quad$ Distance between two adjacent copper tubes, $m$

$x: \quad$ Length direction, $\mathrm{m}$

$y: \quad$ Width direction, $\mathrm{m}$.

Greek Symbols

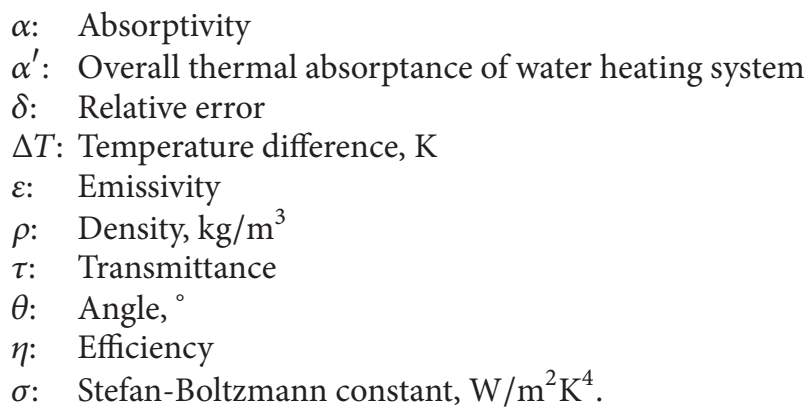

\section{Subscripts}

$\begin{array}{ll}a: & \text { Air } \\ b: & \text { Interior plate of backboard } \\ \mathrm{E}: & \text { Experimental (results) } \\ g: & \text { Front glazing } \\ i: & \text { Differential node “ } i \text { " in } x \text {-direction } \\ \text { In: } & \text { Inlet } \\ j: & \text { Differential node “” in } y \text {-direction } \\ \text { low: } & \text { Lower air channel } \\ \text { out: } & \text { Outlet } \\ p: & \text { Absorbing plate } \\ p 2: & \text { Back face of the absorber plate } \\ R: & \text { Insulation } \\ s: & \text { Sky } \\ S: & \text { Numerical (simulations) } \\ t: & \text { Copper tube } \\ \text { up: } & \text { Upper air channel } \\ w: & \text { Water fluid. }\end{array}$

\section{Conflict of Interests}

The authors declare that there is no conflict of interests regarding the publication of this paper.

\section{Acknowledgments}

This work is supported by the National Key Technology R\&D Program of China (no. 2012BAJ08B04), the International Scientific and Technological Cooperation Program of Anhui Province (no. 1503062012), and the Doctor Program of Anhui Jianzhu University (no. K10099).

\section{References}

[1] T. N. Anderson, M. Duke, G. L. Morrison, and J. K. Carson, "Performance of a building integrated photovoltaic/thermal (BIPVT) solar collector," Solar Energy, vol. 83, no. 4, pp. 445455, 2009.

[2] T. Matuska, "Simulation study of building integrated solar liquid PV-T collectors," International Journal of Photoenergy, vol. 2012, Article ID 686393, 8 pages, 2012.

[3] D. A. G. Redpath, "Thermosyphon heat-pipe evacuated tube solar water heaters for northern maritime climates," Solar Energy, vol. 86, no. 2, pp. 705-715, 2012.

[4] J. W. Ma, W. Sun, J. Ji, Y. Zhang, A. Zhang, and W. Fan, "Experimental and theoretical study of the efficiency of a dualfunction solar collector," Applied Thermal Engineering, vol. 31, no. 10, pp. 1751-1756, 2011.

[5] Z. Yu, J. Ji, W. Sun et al., "Experiment and prediction of hybrid solar air heating system applied on a solar demonstration building," Energy and Buildings, vol. 78, pp. 59-65, 2014.

[6] J. Ji, C. Luo, W. Sun, W. He, G. Pei, and C. Han, "A numerical and experimental study of a dual-function solar collector integrated with building in passive space heating mode," Chinese Science Bulletin, vol. 55, no. 15, pp. 1568-1573, 2010.

[7] W. Sun, J. Ji, and W. He, "Influence of channel depth on the performance of solar air heaters," Energy, vol. 35, no. 10, pp. 4201-4207, 2010.

[8] M. F. El-khawajah, L. B. Y. Aldabbagh, and F. Egelioglu, "The effect of using transverse fins on a double pass flow solar air heater using wire mesh as an absorber," Solar Energy, vol. 85, no. 7, pp. 1479-1487, 2011.

[9] M. A. Karim and M. N. A. Hawlader, "Performance investigation of flat plate, v-corrugated and finned air collectors," Energy, vol. 31, no. 4, pp. 452-470, 2006.

[10] S. Youcef-Ali, "Study and optimization of the thermal performances of the offset rectangular plate fin absorber plates, with various glazing," Renewable Energy, vol. 30, no. 2, pp. 271-280, 2005.

[11] C.-D. Ho, H. Chang, R.-C. Wang, and C.-S. Lin, "Performance improvement of a double-pass solar air heater with fins and baffles under recycling operation," Applied Energy, vol. 100, pp. 155-163, 2012.

[12] N. M. Nahar and H. P. Garg, "Free convection and shading due to gap spacing between an absorber plate and the cover glazing in solar energy flat-plate collector," Applied Energy, vol. 7, no. 1-3, pp. 129-145, 1980.

[13] N. M. Nahar and J. P. Gupta, "Studies on gap spacing between absorber and cover glazing in flat plate solar collectors," International Journal of Energy Research, vol. 13, no. 6, pp. 727-732, 1989.

[14] ASHRAE 93-2010, "Methods of Testing to Determine the Thermal Performance of Solar Collector," 2010.

[15] B. J. Huang and S. C. Du, "Performance test method of solar thermosyphon systems," Journal of Solar Energy Engineering, Transactions of the ASME, vol. 113, no. 3, pp. 172-179, 1991.

[16] T. T. Chow, W. He, A. L. S. Chan, K. F. Fong, Z. Lin, and J. Ji, "Computer modeling and experimental validation of a building-integrated photovoltaic and water heating system," Applied Thermal Engineering, vol. 28, no. 11-12, pp. 1356-1364, 2008.

[17] J. Duffie and W. Beckman, Solar Engineering of Thermal Processes, John Wiley \& Sons, New York, NY, USA, 1991. 
[18] W. C. Swinbank, "Long-wave radiation from clear skies," Quarterly Journal of the Royal Meteorological Society, vol. 89, no. 381, pp. 339-348, 1963.

[19] F. Incropera, D. DeWitt, and T. Bergman, Fundamentals of Heat and Mass Transfer, John Wiley \& Sons, New York, NY, USA, 2007.

[20] A. Bejan, Convection Heat Transfer, John Wiley \& Sons, Hoboken, NJ, USA, 2004.

[21] Z. S. Chen and X. S. Ge, "Theoretical and experimental investigations on determination of the optimum air layer spacing of the flat-plate solar collector with small convective heat loss," Acta Energiae Solaris Sinica, vol. 6, pp. 287-296, 1985. 

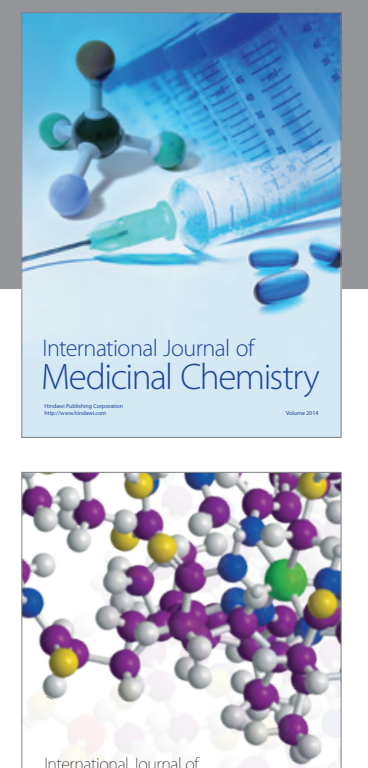

\section{Carbohydrate} Chemistry

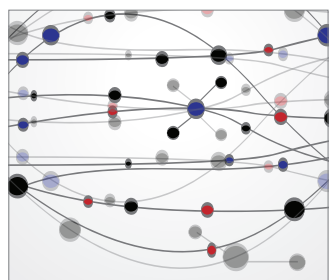

The Scientific World Journal
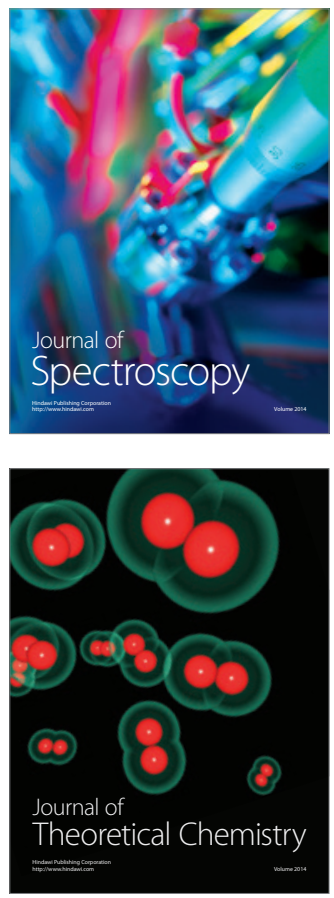
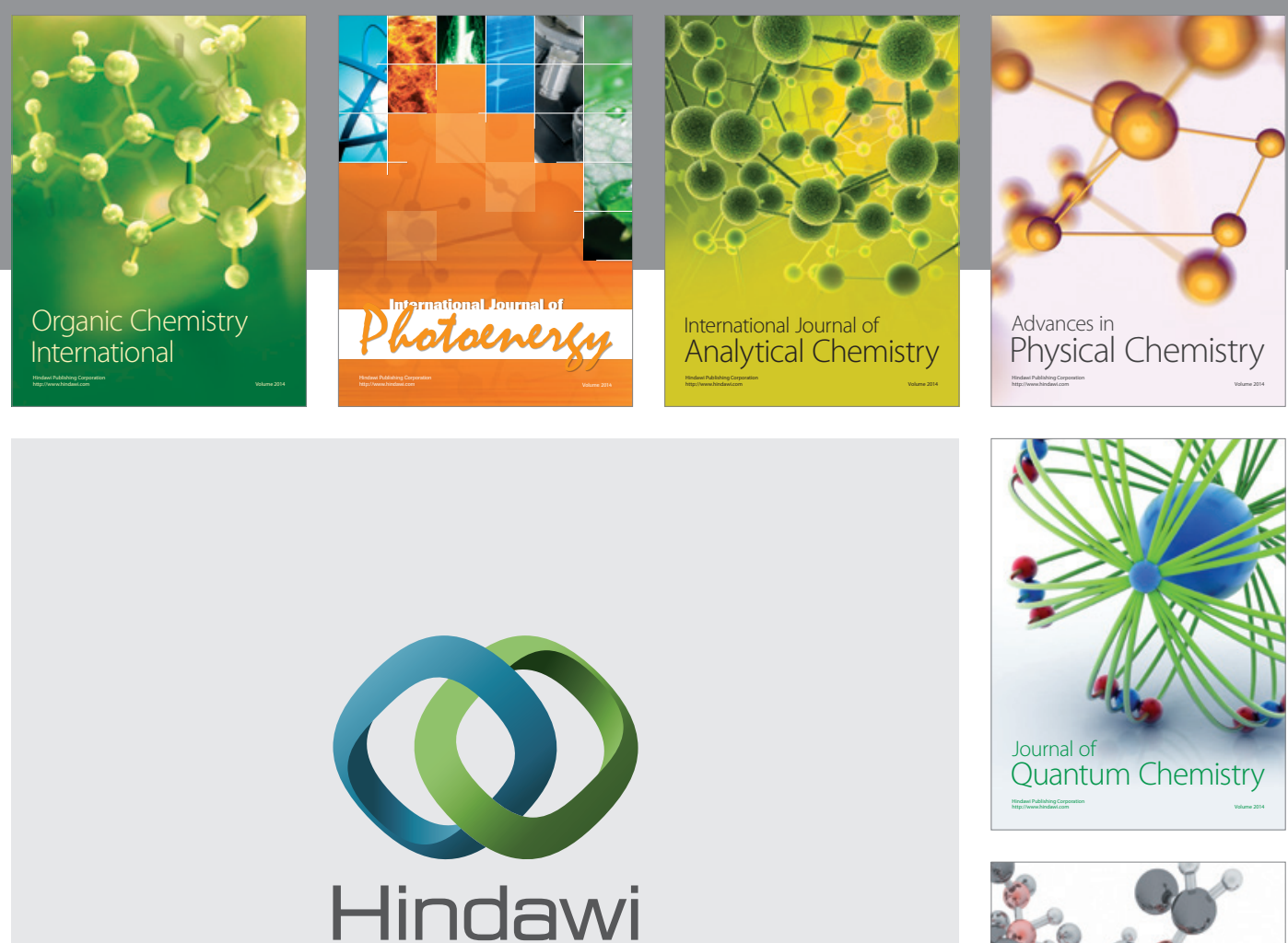

Submit your manuscripts at

http://www.hindawi.com

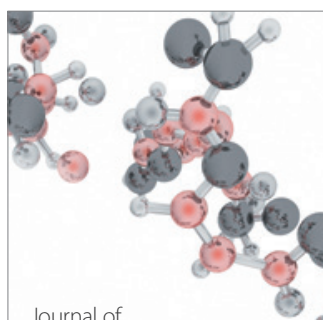

Analytical Methods

in Chemistry

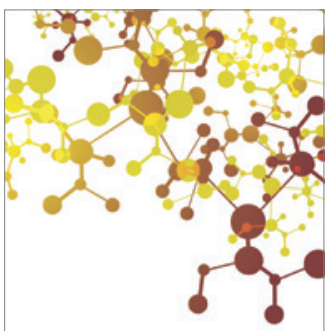

Journal of

Applied Chemistry

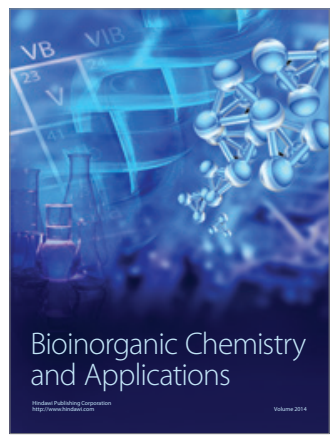

Inorganic Chemistry
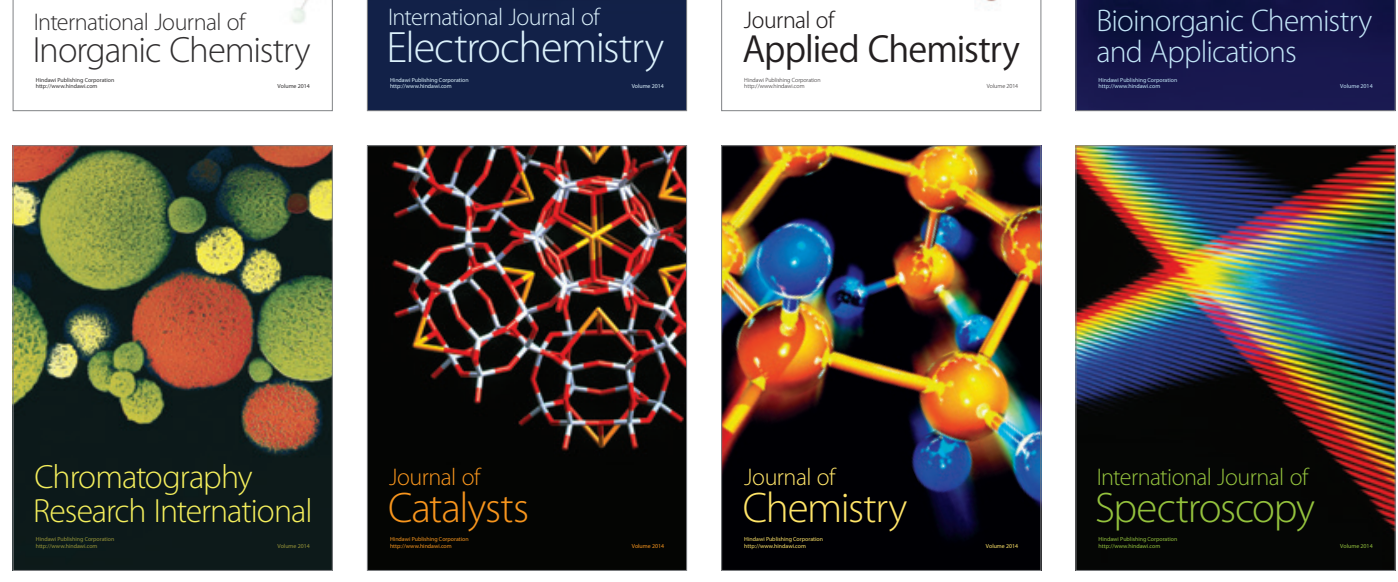